\title{
O ANTINOMISMO TEOLÓGICO EM O CASTELO DE FRANZ KAFKA E SUAS RELAÇÕES COM A CABALA HERÉTICA
}

Jefferson Eduardo da Paz Barbosa Universidade Federal do Rio Grande do Norte

\section{RESUMO}

O objetivo deste artigo é identificar e refletir em $O$ Castelo (2010), de Franz Kafka, a intersecção entre a problemática da crise da tradição, levantada por Walter Benjamin (1987) e Gershom Scholem (1999), e seu desenvolvimento na dialética própria da mística judaica, sobretudo nos movimentos antinomistas que emergiram da Cabala herética e constituíram o niilismo messiânico. O percurso do personagem de $O$ Castelo, mais que peripécias intrigantes, desenvolve, de modo paródico, um exercício exegético próprio da tradição judaica (BLANCHOT, 2002). O Castelo, um objeto carente de substância, agrega em torno de si infinitos comentários, formando um verdadeiro labirinto de palavras. Não existindo senão em seus comentários, o Castelo assemelha-se ao Nome de Deus especulado pelos cabalistas judeus. Para a Cabala herética, Deus é inseparável de sua palavra revelada, a Torá, de modo de que seu Nome é infinitamente interpretável. Pretendemos demonstrar que a relação entre os personagens e os comentários sobre o Castelo, torcidos e profanados como o Nome de Deus entre os cabalistas, faz de Kafka um escritor que explorou magistralmente os limites entre religião e niilismo.

Palavras-chave: Tradição. Interpretação. Cabala herética. Literatura. Franz Kafka. 


\section{1 lntrodução}

K. é um forasteiro e sua vida anterior é pouco importante. Nada nos é permitido saber, exceto em um momento de queixa, onde sugere a vida que teve de abandonar para aceitar o posto de agrimensor. Mas quem conta sua história diz apenas que ele veio da estrada. A vila e a estrada estão interligadas por uma ponte de madeira. "K. permaneceu longo tempo", diz o texto, sobre essa ponte, "e ergueu o olhar para o aparente vazio"(KAFKA, 2010, p. 7). O vazio é aparente porque acima dele, de K., no alto da colina, está o Castelo, totalmente imerso na noite. K. ergue os olhos e vê um aparente vazio. Poderíamos nos perguntar porque ele, não vendo nada, permaneceu tanto tempo em sua atitude. É uma atração misteriosa que apenas se comprova no decorrer da narrativa. $\mathrm{O}$ castelo, mesmo invisível, põe K. obcecado.

Durante seis meses do ano de 1922, Franz Kafka escreveu o enorme fragmento que conhecemos sob o título de $O$ Castelo, publicado postumamente por Max Brod, em 1926. Basicamente, seu enredo trata das diversas tentativas de $\mathrm{K}$. em seu propósito de entrar no Castelo. O que leva $K$. até a vila é sua nomeação de agrimensor, mas sua admissão não é clara, uma vez que parece ter sido um engano cometido por algum funcionário ou setor do Castelo. Os obstáculos que K. encontra em sua caminhada são incompreensíveis, cheios de paradoxos, como se ele não pudesse alcançar a lógica que rege a administração do seu universo. Kafka não tinha a intenção de fazer-se compreender literalmente e isso é unânime em sua fortuna crítica; seja sob o nome de parábola ou metáfora, suas narrativas sempre parecem dizer outra coisa.

Em dado ponto de vista, a postura inicial de K. é motivo bastante para encorajar as leituras de Brod, Hans Schoeps e muitos outros sobre o significado do Castelo, a saber, que ele representa a sede da Graça que os esforços de K. intentam alcançar. Walter Benjamin recusa essa interpretação teológica por ser cômoda e incompatível com o texto literal em muitas ocasiões (BENJAMIN, 1987, p. 153). Benjamin não identifica em Kafka qualquer tendência à conclusão e o que mais caracteriza tanto $O$ Processo quanto $O$ Castelo (aplicável também aos problemas com o matrimônio e a escrita) é o adiamento. $\mathrm{O}$ acusado se arrasta ao longo de seu processo sem que nunca a sentença seja anunciada do mesmo modo que $\mathrm{K}$. é obstado por inúmeros contratempos que o impedem de falar com o Castelo. É esse retardo do fim que põe todas as interpretações em negati- 
vo, com soluções suspensas no indeterminado. O destino de K. é adiado desde o início até às páginas finais, em que é levado mais uma vez para o labirinto de contratempos que se interrompe bruscamente.

Outro ponto de vista anuncia talvez o contrário. A postura de K. diante do vazio aparente é a fascinação exercida pelo deus absconditus, o sentido e a verdade que está lá, mas não está disponível ou então sua inteligibilidade degenerou em uma transmissão burocratizada, encarnada em figuras nada atraentes, como Klamm, o prefeito, Bürgel, Erlanger, etc. Se K. se mostra tão insistente em compreender essa verdade, mesmo que sua substância pareça diluir-se na total ausência de significado, é porque ela se mantém como possibilidade da redenção uma vez compreendida. Mas é porque o adiamento dessa compreensão é infinito que a redenção nunca chega. Em Kafka, o acusado ou o forasteiro seguem à deriva indefinidamente sem sabermos até quando. Talvez até o ponto em que eles, padecendo o sofrimento da espera, se convertam em juízes, o que caracterizaria uma ruptura messiânica e, por consequência, uma ruptura com a Lei. A ideia de que a Lei só ensinará toda a sua essência quando for subvertida foi alimentada pelo messianismo sabbataísta mais extremo, onde a Cabala se encontra com os movimentos antinomistas no interior do judaísmo (FORSTER, p. 2008, p. 9). ${ }^{1}$ Mas entramos, nesse caso, em outra abordagem.

Do início ao fim o objetivo de K. é esclarecer sua função e o único meio para isso é entrando em contato com o Castelo. O forasteiro, que já não tem origem, também não pertence à vila e tampouco os funcionários lhe dão resposta definitiva. Essa condição pode caracterizar, conforme a interpretação de Hannah Arendt, o exílio judeu, ou o judeu como pária em busca da assimilação, podendo finalmente se tornar indistinguível (ARENDT, 2005, p. 66). Tornar-se funcionário do Castelo, então, não seria redimir-se no sentido espiritual, é ser liberado da vida incerta e sem sentido, não humana, que fervilha à margem da Lei. K. não exige direitos especiais, quer apenas integrar-se de forma regular a sua nova vida. De fato, não pede menos que isso, mas é justamente o que lhe é recusado. A redenção também pode ser obtida junto aos aldeões, mas só em aparência, o que nos remete à proposta que Pepi faz a K. no último capítulo, insistindo para que ele, sem abandonar a condição de forasteiro, fosse viver nos porões de alguma casa. $\mathrm{O}$ romance é interrompido sem sabermos qual sua decisão. K. não seria, conforme essa visão, um antinomista, alguém que nega as leis impostas, mas alguém que busca viver sob elas de maneira justa e humana. 
Uma parte da crítica em torno de Kafka não hesita em vincular o antinomismo de seus heróis à visão gnóstica do mundo. Também seria o caso de não encontrarmos respaldo textual, o que não invalida uma aproximação onde se considere sua estrutura. A relação com a visão gnóstica do mundo não é despropositada quando observamos no gnosticismo e na gnose herética de Jacob Frank, por exemplo, a consideração do mundo como um lugar infernal gerido por leis indignas (SCHOLEM, 1999, p. 180). A relação com o gnosticismo pode ir desde uma evocação de Brod em suas memórias (BENJAMIN, 1987, p. 141-142) até afirmações mais pontuais na interpretação de Günther Anders. Quando observamos o caráter plurívoco da autoridade em Kafka e seus efeitos no mundo e nos personagens, somos conduzidos a uma teodicéia, onde a existência do mal é incompatível com a existência de Deus. A origem do mal no mundo só poderia derivar de um "Deus mau", de um demiurgo, como chamaram alguns gnósticos. Por isso Anders afirma ser Kafka um marcionista, isto é, um adepto ou simpatizante das ideias de Marcião de Sinope, o heresiarca do século II, d. C. para quem o Deus do Antigo Testamento era radicalmente distinto do Deus anunciado por Jesus Cristo, sendo o primeiro o Deus da Lei e da Criação (portanto, um Deus maligno) e o segundo, o Deus da redenção. ${ }^{2}$

Assim como os heróis de Kafka fracassam na tentativa de interpretar o insondável (o Tribunal, o Castelo, a Lei), o leitor fica sem resposta definitiva. $\mathrm{O}$ fio de Ariadne costuma perder-se no meio do caminho. Tanto no mundo kafkiano, como na experiência de seus investigadores, as mensagens resistem à interpretação definitiva. Talvez seja um traço do judaísmo em Kafka, apresentar uma linguagem que por ser humana já não pode dizer a verdade, forçando à peregrinação através do labirinto que resultou da Queda. Ou talvez esteja mais próximo de certa visão da Cabala luriânica, onde cada palavra da Torá possui seiscentos mil rostos, planos de sentido ou entradas, de acordo com o número de filhos de Israel que se encontravam no monte Sinai. Desde pronto já estamos em face do labirinto hermenêutico que Kafka, de maneira ambígua, isto é, crítica, colheu de sua tradição.

\section{Kafka, Benjamin e Scholem: a tradição como la- birinto}

Nada é mais evidente em $O$ Castelo que seu mundo labiríntico. Não são, todavia, labirintos enquanto estruturas físicas, pois a vila é um pequeno aglomerado nas proximidades do Castelo. Muitos poderiam afir- 
mar que esse mundo frio e cinzento é o próprio inferno, o inframundo, com todos os seus labirintos, como aquele atravessado na Eneida por seu herói. No labirinto de Kafka inexiste qualquer possibilidade de salvação, pois não se trata de franquear muros, mas de encontrar uma verdade que se perdeu, talvez para sempre, no volume de seus comentários, ou que mantém-se guardada por uma administração obscura cerrada sobre si mesma, inacessível, cuja autoridade fracionada e hierarquizada é vazia de propósito real. Aquele que aguarda no final do conto "Uma mensagem imperial" ( $O$ médico rural), que pode muito bem ser o leitor de $O$ Castelo, é da mesma família de K. O imperador, no leito de morte, enviou-lhe uma mensagem, mas ela nunca chegará ao seu destino. A propósito, é de um homem morto (possível metáfora de Deus) que se espera a mensagem. O labirinto de K. é composto de comentários, de inúmeras versões e exegeses sobre o Castelo contadas por todos os moradores da vila. Esse labirinto exegético expressa bem a relação de Kafka com o judaísmo, que Benjamin vislumbrou sob o signo de uma "enfermidade da tradição" onde a verdade perde toda sua consistência (MÒSES, 1997, p. 197).

Por muitos anos Benjamin e Gershom Scholem mantiveram uma correspondência cujo centro foi a interpretação da obra de Kafka, interpretação que excedeu enormemente a ideia de que ele buscou em sua escritura uma singularidade narcísica. Dentre as muitas ideias que os dois intelectuais levantaram, não podemos deixar de destacar a questão do distanciamento da tradição e o nada da Revelação. A "enfermidade da tradição", apontada por Benjamin, resulta da secularização que aclimatou (em seu processo de assimilação) as famílias judias à cidade burguesa moderna. Quando Kafka se queixa de seu pai pelo judaísmo reduzido a nada que lhe fora transmitido (em Carta ao pai), fica bastante clara a crise espiritual de seu tempo. Que não restasse a Kafka senão livrar-se desse judaísmo de mentira o mais rápido possível faz de sua relação com a religião um campo obscuro, pontuado apenas por sugestões, ou sussurros, como diria Benjamin. Seu mundo ficcional está despojado de todos os ornamentos da tradição, mesmo mantendo, de forma problemática, a tríade judaica: a Lei, a Revelação e o comentário (ALTER, 2002, p. 38). Podemos ler em uma carta de Benjamin:

Kafka escutava atentamente a tradição, e quem aguça o ouvido, não vê. [...] Essa escuta é intensa sobretudo porque ao que escuta só lhe chega o menos claro. Aí não há nenhuma doutrina a aprender nem ciência que se possa conservar. O que deve ser capturado no voo não 
são coisas que estejam destinadas a um ouvido. Isto implica um estado de coisas que caracteriza rigorosamente a obra de Kafka em sua parte negativa. (Sua parte negativa será, desde já, muito mais rica em possibilidades que a positiva). A obra de Kafka representa uma enfermidade da tradição (BENJAMIN; SCHOLEM, 1987, p. 227).

Os dois críticos discordam em muitos pontos. Benjamin rejeita a interpretação teológica praticada por Scholem, ainda que ela desperte seu interesse em algum momento. $\mathrm{O}$ que na verdade repugnava a Benjamin era a teologia positiva que Max Brod formou em torno de Kafka. No caso de Scholem, o sentido positivo da Revelação estava perdido, o que o tornava mais próximo de uma especulação aos moldes da teologia negativa, que a partir dos anos cinquenta será aproximado do messianismo e do niilismo religioso (MÒSES, 1997, p. 182). É apenas nesse sentido, de um nada da Revelação, que se pode identificar em Kafka uma teologia ou concebê-lo como homo religiosus.

Scholem escreve: "O mundo de Kafka é o mundo da Revelação, claro que na perspectiva na qual se dirige de novo a seu próprio nada" (BENJAMIN; SCHOLEM, 1987, p. 131). É importante entender que esse nada não se refere somente à ausência de Deus, mas ao que ela implica. $\mathrm{O}$ que é revelado no judaísmo, o que é emanado da voz de Deus e é recebido por Moisés é a Torá, isto é, a Lei ou Doutrina. O que Scholem está dizendo, portanto, é que no mundo de Kafka a Lei perdeu a substância de sua autoridade. Sabemos que em seus romances a Lei existe e é válida (pois é o mundo da Revelação), mas já não possui significado, está vazia. Em resposta a Benjamin ele escreve, ainda:

Perguntas o que entendo por "Nada da revelação". Refiro-me a um estado em que esta aparece vazia de significado, no que se bem se afirma e é válida, não obstante, não significa. Quando falta a riqueza da significação e o que se manifesta, reduzido a um ponto zero de conteúdo próprio, todavia, não se desvanece (e a revelação é algo que se manifesta), então surge seu nada (BENJAMIN; SCHOLEM, 1987, p. 145).

Benjamin entende a secularização como índice de que a tradição não pode mais oferecer uma explicação do real. Por isso o seu gradual esquecimento e inevitável desaparição. Scholem, que viu no movimento sionista e na constituição do Estado de Israel um movimento secularizador que faria naufragar de vez o hebreu como língua sagrada, não deixa de defender que o problema da tradição é sua transmissibilidade, não sua morte. A Revelação se tornou incompreensível, mas não significa que 
nunca mais falará aos homens. O grande trabalho de Scholem foi revolver o solo da tradição, recuperando uma antitradição esquecida que passa pela Cabala herética e o niilismo messiânico. A tradição sofre flutuações, passa por períodos de silêncio, e nisso consiste sua historicidade.

Benjamin destaca em Kafka a presença dos estudantes incansáveis, sempre afundados nos livros, mas que perderam a Escritura (BENJAMIN, 1987, p. 164). Em outra carta, Scholem se refere a essa passagem e discorda que a Escritura tenha sido perdida. Na verdade, os estudantes são discípulos que não podem mais decifrar (BENJAMIN; SCHOLEM, 1987, p. 131). Scholem descobre na Cabala uma tradição oral rebelde a toda escritura, cujo conhecimento a ser transmitido não é um corpo doutrinal ou verdade última, mas um horizonte de leitura ou interpretação. A direção de leitura, ao fixar-se na forma escrita, necessita de outra chave interpretativa. Chega-se ao ponto em que não há nada a ser transmitido senão a possibilidade da transmissão (MÒSES, 1997, p. 199). É como um "véu de névoa" que Scholem vê a tradição mística judaica, uma tradição em que a verdade, ironicamente, pode tudo menos ser transmitida (SCHOLEM, 1999, p. 224). Se para Benjamin a consistência da verdade foi perdida, para Scholem ela segue oculta. Kafka seria um amplo relato desse ocultamento, lançando permanentemente a pergunta acerca da verdade. Seus personagens não possuem a chave que poderia abrir a porta correta do grande edifício talmúdico e se perdem no labirinto textual dos comentários.

\section{A antinomia diante do Nome de Deus, o infinita- mente interpretável}

Voltamos à atitude inicial de K. Sobre a ponte de madeira, por longo tempo, ele ergue o olhar para o aparente vazio. É em torno dessa aparência que se levanta todo o labirinto exegético. Por trás de todos os comentários não há fundo. Só há um abismo infinito de palavra, nunca a Lei, mas só as indicações de sua leitura. A primeira página do romance poderia confirmar Benjamin e sua tradição enferma, não fosse o termo "aparente" (scheinbare) que Kafka antepõe ao "vazio". O Castelo está lá, no alto da colina, ainda que não pareça.

Maurice Blanchot, em um texto tardio sobre $O$ Castelo, não mais considerando Kafka um escritor da "solidão essencial", toca um ponto que também observamos em Benjamin e Scholem. Ele reconhece que apesar de não tratar explicitamente da Escritura como problema, ela faz 
parte de sua estrutura como exercício interminável do comentário. O impressionante em K. não é que ele vai inutilmente de um ponto a outro da aldeia, mas sim que vai de uma exegese a outra, escutando cada uma delas atentamente, mesmo tomado pelo cansaço, como quando ouve o comentário de Bürgel. Todas as interpretações submetem-se ao seu exame, logo intervindo e discutindo interpretações alternativas. $\mathrm{O}$ capítulo " $\mathrm{Na}$ catedral", em O Processo (1997), onde Joseph K. e o padre discutem a interpretação da parábola "Diante da Lei" é similar ao último capítulo de $O$ Castelo, onde Pepi urde um longo comentário sobre a relação entre K. e Frieda. Nos dois casos, os heróis kafkianos questionam a interpretação apresentada e oferecem seu ponto de vista. Conforme Blanchot, seria fácil comparar esse movimento com a dialética talmúdica (BLANCHOT, 2002, p. 164). A sucessão interminável de versões exegéticas trata, no final das contas, da possibilidade de interpretar $O$ Castelo - ou, em último caso, de escrevê-lo. Blanchot escreve:

[...] $O$ Castelo não é senão isso, e a força das imagens, a fascinação das figuras, a atração decisiva do relato constituem sua única verdade, verdade tal que sempre parece dizer a respeito mais do que tudo que se possa dizer, com o que introduz o leitor, mas antes que nada o narrador, através tormento de um comentário sem fim (BLANCHOT, 2002, p. 166).

O vazio que o Castelo representa parece dizer mais que tudo o que se possa dizer sobre ele, mas também é verdade a afirmação inversa, de que ele diz infinitamente menos. A precariedade que ronda a peregrinação de K. não se limita ao interior das habitações da vila e à condição sub-humana dos aldeões. Apesar do exaustivo comentário sobre o Castelo, todas as respostas que se pode obter são insuficientes. O Castelo parece não existir senão em seus comentários, mas estes são sempre insuficientes. Para Blanchot ele é uma instância indiferente a toda avaliação, uma instância neutra. Colocar o neutro no lugar da Lei, ou do deus absconditus, é talvez uma forma de abolir o seu mistério. Todavia, se visamos apenas o conceito, ainda se enquadra numa teologia negativa.

Se o neutro é o que não pode ser avaliado, não é finito nem infinito. Por outro lado, o que o Castelo suscita é um comentário infinito, precário e fragmentado, de modo que somente o compreendemos através dele, pois não temos acesso à unidade pura, mas à multiplicidade em que se dispersa. O posto de Absoluto ocupado pelo Castelo também é ocupado pelo Uno além de toda inteligibilidade. Sem dúvida, à primeira vista, não 
haveria nada mais estranho ao judaísmo ortodoxo que um Deus oculto, sem rosto e impessoal. Na tradição mística da Cabala, que segundo Scholem desenvolve-se nos séculos XII e XIII, na Provença e na Catalunha, é possível encontrar as primeiras alusões a um Deus oculto dentro do judaísmo ${ }^{3}$.

As religiões monoteístas se desenvolveram no período medieval cercadas por duas heranças em tensão: fontes provindas do mundo religioso canônico, cujas escrituras foram recebidas por revelação, e o mundo do pensamento especulativo da filosofia grega (SCHOLEM, 2008, p. 16). Em outras palavras, a tensão se arma entre o Deus da Bíblia (para o judeu-cristianismo) e o Uno de Plotino. O Deus da Bíblia não é gerado ao cabo de um percurso racional. Ele se dá na experiência da comunidade e na revelação individual, ou é dado como incontestável na manifestação da Criação. ${ }^{4}$ É um Deus que possui vontade e consciência incompreensíveis, mas apreensíveis como Sabedoria. É o Deus que se dirige a Jó e demonstra provas incontestáveis de seu poder. Jó pergunta a Deus porque é permitido no mundo a injustiça; Deus responde perguntando-lhe se presenciou a Criação. É uma pergunta que lança sobre Jó a humilhação da criatura. A revelação de Deus implica, portanto, a revelação de sua personalidade una. Precisamente contrário ao Deus bíblico, o Uno de Plotino é alheio a toda determinação e é alcançado ao término de um caminho filosófico. Ele é pura quietude, ausência de consciência, e só pode ser pensado mediante as emanações que dele fluem e constituem os três níveis do ser: o intelecto, a alma do mundo e a natureza. Não há, como no Deus bíblico, uma revelação.

Podemos concordar com Scholem e considerarmos Kafka um adepto da Cabala herética. No judaísmo, o encontro entre neoplatônicos e cabalistas resultou em uma complexa noção de Deus: a unidade indiferenciada do que não tem fim, ou Ein-sof ${ }^{\beta}$, que se manifesta e revela em seus nomes, em sua linguagem. Os comentários sobre o Castelo são intermináveis porque ele próprio é o que não acaba. É importante lembrar que o mundo de Kafka é o mundo da Revelação que se volta para o seu próprio nada. A palavra revelada se volta para o seu vazio, onde os esforços de K. esbarram inapelavelmente. O meio que é a linguagem é precário porque seu interior nunca é revelado, ainda que seja a substância da Revelação. Essa é uma visão partilhada pelos cabalistas, "a convicção de que a linguagem, o medium no qual o espírito do homem se concretiza, possui um lado interior, ou seja, um aspecto que não se revela totalmente 
nas relações de comunicação entre os seres" (SCHOLEM, 1999, p. 10), formando o ponto de partida de todas as teorias místicas da linguagem das quais também fazem parte os cabalistas. Na Cabala, o Nome de Deus é constituído por todas as letras do hebreu. Nesse sentido, o Nome de Deus pode ser a própria Torá ${ }^{6}$, mas também pode ser o vazio, a ausência de significação, do mesmo modo que as 22 letras do alfabeto hebreu não possuem significado. Podemos ler em Scholem, que, ao falar da ausência de significado do Nome de Deus, aponta para o problema da tradição comentado até aqui:

O fato de o Nome de Deus ser desprovido de significação é um indicativo de sua posição no centro da revelação, servindo-lhe de base. Por trás de toda revelação de um sentido na linguagem e, como os cabalistas dizem, através da Torá, situa-se esse elemento para além do sentido e que, ao mesmo tempo, o possibilita. Sem ter um sentido, ele próprio confere um sentido a tudo. Aquilo que para nós é reconhecível na Criação, o Nome de Deus, é infinitamente interpretável e reflete-se em nossa linguagem. [...] O que tem significado, sentido e forma, não é essa palavra propriamente, mas a tradição dessa palavra, sua intermediação e reflexão no tempo. Essa tradição, que possui sua própria dialética, transforma-se e converte-se eventualmente em um sussurro silencioso e bafejante, podendo haver épocas, como a nossa, onde quando ela já não pode ser mais transmitida e quando essa tradição emudece (SCHOLEM, 1999, p. 61).

Entre outros aspectos, o que se diz no trecho é que não há nada fora da tradição, o significado do Nome de Deus, da Torá, é sua própria transmissão. Se Deus não está fora da Torá e a Torá não está fora de Deus, pode-se concluir que na concepção cabalista do Nome de Deus, que o funde a sua Revelação, não há fora do texto (IDEL, 2007, p. 114). Por isso Scholem encara a tradição como algo plástico de onde se pode extrair ainda sua força viva na medida em que nele se aprofunde. É preciso pontuar que a Cabala e sua concepção de Deus como "o sem fim" (Ein-sof) excede, ou mesmo subverte, a compreensão plotiniana do Uno. As significações de Deus são possíveis porque sua unidade é inseparável de sua textualidade; sua unidade é inseparável de sua encarnação no múltiplo revelado. A infinitude de Deus na tradição cabalística e o enfraquecimento da distinção de sua pessoa aumentam a obscuridade de sua mensagem, o que proporciona, em consequência disso, a posição ativa do exegeta. Se voltarmos ao texto de Kafka, observamos que a presença do Castelo, enquanto origem metafísica, nos permite conceber a linguagem como 
exposição e desdobramento de seu Nome na infinita plasticidade de seus comentários. Por isso podemos entender a postura de K. como subversiva, em confronto com todas as interpretações que lhe são apresentadas.

O filósofo e místico cabalista judeu mais importante nessa concepção "textual" de Deus (concepção "textocêntrica", diria Moshe Idel) ${ }^{7}$ foi Abraão Abuláfia, nascido em Saragossa, no século XIII. A Cabala de Abuláfia possui um duplo aspecto que envolve práticas meditativas: a Cabala extática e a Cabala dos Nomes de Deus. A contemplação das letras do alfabeto hebreu e a recitação dos Nomes de Deus é um método para atingir uma experiência mística fundamental, mas também um método exegético avançado. A técnica da combinação das letras do alfabeto permite ao místico acessar os estratos mais profundos da Escritura (IDEL, 1989, ix). A atitude de Abuláfia com relação a Deus e a Torá atraiu a má fama de que gozou em seu século. A ideia de que o segredo da Escritura será atingido a partir da permutação de suas frases e de suas letras, a fim de que novos significados emerjam, desenterrando todos os Nomes de Deus, pode ser vista como uma forma de subversão e foi reconhecida como prática herética.

Que os místicos da Cabala tenham sido inseridos no grupo dos heréticos demonstra uma das facetas mais peculiares da relação entre experiência mística e autoridade religiosa. O místico atravessa as positividades doutrinárias e vai em direção à experiência fundadora, onde pode adquirir, por sua vez, uma nova autoridade. Essa foi a relação de Abuláfia com a Escritura mediante a Cabala, isto é, descobrir as novas dimensões que as positividades tendem a ocultar em suas cristalizações. Essa oposição constitui a dialética própria da tradição mística e nela se funda a proliferação de comentários. A revelação obtida pelo místico através de sua experiência não é a verdade absoluta, mas uma nova chave que o permitirá ler de outra maneira a Revelação, pois a palavra de Deus, que é Ele próprio, tem de ser infinita, devendo suscitar uma busca igualmente infinita por novas chaves. Orígenes relata que um sábio hebreu certa vez lhe disse que a Escritura era uma grande casa com muitos aposentos. Diante de cada um deles estava uma chave, mas não a correta (SCHOLEM, 2001, p. 13). Não será, de fato, similar ao que lemos em $O$ Castelo? K. está em face da Revelação, mas não tem a chave que lhe permite adentrar em seu mistério. Por isso que Scholem diz que aqueles estudantes incansáveis destacados por Benjamin não perderam a Escritura, mas apenas não podem mais lê-la adequadamente. 
Essa concepção de uma divindade cuja palavra se oculta sob seiscentos mil rostos, concepção que afirma ao mesmo tempo sua presença e sua ausência, presença que se dá mediada por uma distância infinita, como a que separa a mensagem do imperador de seu destinatário, é a que mais convém ao "niilismo religioso" de Kafka e seu questionamento sem fim. Mais que ninguém, Kafka estendeu ao máximo o limite entre niilismo e religião. Em nossa época, talvez ele possa nos ensinar a profanar os textos sagrados, a torcê-los, não para que sejam anulados, mas para que possam, pela força da plasticidade que sua fábula contém, revelar seus sentidos. Não será essa a prática que tem iluminado nossa época, seja com Martin Heidegger e os gregos, seja com a atitude desconstrutora de Jacques Derrida? 


\section{THE THEOLOGICAL ANTINOMISM IN THE CASTLE OF FRANZ KAFKA AND ITS RELATIONSHIP WITH THE HERETICAL KABBALAH}

\section{ABSTRACT}

The purpose of this paper is to identify and reflect on Franz Kafka's The Castle (2010), the intersection between the problem of the crisis of tradition, raised by Walter Benjamin (1987) and Gershom Scholem (1999), and its development in the dialectic of the Jewish mysticism, especially in the antinomian movements that emerged from heretical Kabbalah and constituted Messianic nihilism. The journey of the character of The Castle, rather than intriguing peripécies, develops, in a parody, an exegetical exercise proper to the Jewish tradition (BLANCHOT, 2002). The Castle, an object devoid of substance, surrounds itself with infinite comments, forming a veritable labyrinth of words. Only in his commentaries, the Castle resembles the Name of God speculated by the Jewish Kabbalists. For heretical Kabbalah, God is inseparable from his revealed word, the Torah, so that his Name is infinitely interpretable. We intend to demonstrate that the relationship between the characters and the comments about the Castle, twisted and desecrated as the Name of God among the Kabbalists, makes Kafka a writer who masterfully explored the boundaries between religion and nihilism.

KEYWORDS: Tradition. Interpretation. Heretical Kabbalah. Literature. Franz Kafka.

\section{NOTAS}

${ }^{1}$ Esse aspecto é relevante na medida em que o modo como a Torá é vista pelos sabbataístas propiciou o surgimento de figuras revolucionárias que viam na ruptura da lei um modo de realizar, na história, o reino dos justos. Entre essas figuras, estão Franz Kafka, Walter Benjamin, Gershom Scholem, entre outros (FORSTER, 2008, 
p. 9). Uma leitura que destaca os aspectos anarquista ou utópico libertário da obra de Kafka pode ser encontrada em LÖWY, Redenção e Utopia, 1989, pags. 67-84. 2 "Em Kafka revive, de fato, a ideia, marcionista, segundo a qual o Deus-criador é “demiúrgico”, portanto, 'mau' - e a correspondência é tanto mais surpreendente quanto, em Marcião, esse Deus-criador (de forma diversa que o Deus do amor) é, ao mesmo tempo, o Deus da 'Lei', do Velho Testamento: também em Kafka coincidem a instância divina, a lei e a "maldade"' (ANDERS, p. 118). Encontramos na tese de Claudio Willer, sobre poesia e gnose, a informação de certo círculo marcionista frequentada por Kafka e seus amigos (WILLER, Claudio. Um obscuro encanto: gnose, gnosticismo e a poesia moderna, p. 8). Essa visão também é fornecida por CORNGOLD; BRENO, "Kafka (with Nietzsche) as neo-gnostic thinkers", In. Kafka: The ghost in the machine. Illinois: Northwestern University Press, 2011, e Éric Lecler, que a partir da relação com a gnose marcionista e a Cabala justifica o messianismo revolucionário de Kafka (LECLER, 2013, p. 235). Sobre a visão gnóstica do mundo, ver JONAS, Hans. La religión gnóstica. Madrid: Siruela, 2000.

${ }^{3} \mathrm{Na}$ verdade, um dualismo de Deus pode ser constatado na Antiguidade tardia. Scholem observa em vários momentos que o gnosticismo do século II d. C. também formou o pensamento de alguns judeus helenizados. O teólogo judeu alexandrino mais próximo do gnosticismo foi Cerinto. Segundo Epifanio de Salamis, Cerinto foi o primeiro teólogo judeu a ensinar a diferença entre o Deus Supremo e o Deus Criador que, mesmo sem identificá-lo ao Deus do Antigo Testamento (não consta no testemunho de Epifanio, tampouco em Ireneu de Lyon), apresenta semelhanças com Marcião de Sinope. Cf. TORRENTS, Los gnósticos, 2000, p. 24. 4 "Suas manifestações são tão tangíveis que não necessitam de nenhuma prova ulterior; os efeitos do seu poder são legíveis na natureza e na história, sobretudo nesta última, e quando se oculta não é que por natureza seja oculto, sim porque nós não somos dignos de sua revelação, porque estendemos ao seu redor um véu fabricado por nós mesmos" (SCHOLEM, 2008, p. 12).

${ }^{5}$ Ein-sof ou Ain-sof, denota Deus antes de seu automanifestar-se, anterior as suas emanações (Sefirót). É o absoluto impessoal cuja "existência" não pode ser descrita por nenhum atributo. Podemos ler no Zohar: "Antes que Ele desse qualquer forma ao mundo, antes d'Ele produzir qualquer forma, Ele estava sozinho, sem forma e sem semelhança com qualquer outra coisa. Quem então poderá compreender como Ele era antes da Criação? Assim, é proibido fornecer a Ele qualquer forma ou semelhança, ou mesmo chamá-Lo por seu nome secreto, ou indicá-Lo por uma única letra ou um único ponto" (CAMPANI, 2011, p. 290)

${ }^{6}$ Segundo Yosef Chicatilla, cabalista espanhol do século XIII, a Torá é a explica- 
ção do Nome de Deus. Ele escreve: "Sabei que a Torá é algo como a explicação do Nome de Deus e um comentário do Tetragrama YHVH" (apud. MILMANIENE, 2007, p. 110). O Tetragrama, na mística judaica, é a fonte de todos os outros nomes. Em si mesmo, possui um sentido oculto, estruturado numa combinatória onde as letras se dispõem numa diversidade infinita. Essa combinatória forma um tecido metamorfo e variável que se refere à Torá (SCHOLEM, 1976, p. 46).

${ }^{7}$ Moshe Idel compara a hermenêutica cabalística com algumas visões contemporâneas do texto e da leitura. Se para Roland Barthes a soberania do leitor implicava a morte do autor, que foi um movimento similar ao realizado por Jacques Derrida, ao propor a elipse da autoria (da presença logocêntrica), para Moshe Idel o que atribui à Cabala criativa a infinitude de significados é a identificação entre autor e texto. Segundo ele "é a presença do autor infinito no seio do texto canônico que garante a possibilidade de extrair uma infinidade de significados. A ideia de um Deus infinito atenua o caráter distinto de Sua pessoa e a claridade de suas mensagens. Isto deixa ao leitor a tarefa de redefinir o tempo assim como o conteúdo do livro que está lendo" (IDEL, 2007, p. 116).

\section{REFERÊNCIAS}

ALTER, Robert. Anjos necessários: tradição e modernidade em Kafka, Benjamin e Scholem. Rio de Janeiro: Imago, 2002.

ANDERS, Günther. Kafka: Pró e contra. São Paulo: CosacNaify, 2007.

ARENDT, Hannah. La tradición oculta. Buenos Aires: Paidós, 2005.

BENJAMIN, Walter. Magia e técnica, arte e política. São Paulo: Brasiliense, 1987.

BENJAMIN, W.; SCHOLEM, G. Correspondência 1933-1940. Madrid: Trotta, 1987.

BLANCHOT. Maurice. De Kafka a Kafka. Madrid: Editora Nacional, 2002.

BRÉHIER, Émile. La filosofía de Plotino. Buenos Aires: Sudamerica, 1976.

CAMPANI, Carlos. Fundamentos da Cabala: Sêfer Yetsirá. Pelotas: Editora UFPEL, 2011.

FORSTER, Ricardo. La cabála y la travesía del mal. Revista Digital de Estudos Judaicos. Belo Horizonte, v. 2, n. 3, out, 2008.

IDEL, Moshe. Jacques Derrida and kabbalistic sources. In Judeities: 
Questions for Jacques Derrida, EUA: Fordhan University Press, 2007. Language, Torah, and Hermeneutics in Abraham Abulafia. New York: State University of New York Press, 1989.

KAFKA, Franz. O Castelo. São Paulo: Companhia das Letras, 2010. . O Processo. São Paulo: Companhia das Letras, 1997.

. Obras Completas III: Narraciones y otros escritos. Espanha: Galaxia de Gutenberg, 2003.

LECLER, Éric. L'Absolu et la littérature: du romantisme allemand à Kafka. Paris: Classiques Garnier, 2013.

MILMANIENE, Magalí. La tradición mesiánica judía ya la influencia de Gershom Scholem en la obra de Walter Benjamin. Tese (Universidad de Buenos Aires), 2007.

MOSĖS, Stéphane. El ángel de la historia: Rosenzweig, Benjamin, Scholem. Madrid: Cátedra, 1997.

SCHOLEM. Gershom. La Cábala y su simbolismo. México, 2001. . Conceptos basicos del judaismo. Madrid: Trotta, 2008. . Los orígenes de la cábala. Barcelona: Paidós, 2001. . Judaica III. São Paulo: Perspectiva, 1999.

TORRENTS, José. Los gnósticos. Madrid: Gredos, 2000.

Recebido: 01/02/2018

Aceito: 07/06/2018 